\title{
ACTIVATED CARBONS FROM VEGETAL RAW MATERIALS TO SOLVE ENVIRONMENTAL PROBLEMS
}

\author{
Viktor Mukhin ${ }^{a^{*}}$, Tudor Lupascu ${ }^{\mathrm{b}}$, Nadejda Voropaevac, Yuriy Spiridonov ${ }^{\mathrm{d}}$, \\ Nicolay Bogdanoviche, Vasiliy Gur'janov ${ }^{\mathrm{a}}$ \\ ${ }^{a}$ ENPO “Neorganika”, 4, K. Marks str., Electrostal 144001, Russian Federation \\ ${ }^{b}$ Institute of Chemistry, Academy of Sciences of Moldova, 3, Academiei str., Chisinau, MD 2028, Republic of Moldova \\ 'SRI of rapeseed RAAS, 26, Boevoi proezd, Lipetsk, 398037, Russian Federation \\ ${ }^{d}$ SRI of phytopathology of RAAS, Bolshie Vyazemy, 143050, Odintsovo district, Moscow Region, Russian Federation \\ ${ }^{e}$ North Arctic Federal University, 17, North Dvina Quay, Arhangelsk, 163002, Russian Federation \\ *e-mail:neorg.el@mail.ru
}

\begin{abstract}
Technologies for active carbons obtaining from vegetable byproducts such as straw, nut shells, fruit stones, sawdust, hydrolysis products of corn cobs and sunflower husks have been developed. The physico-chemical characteristics, structural parameters and sorption characteristics of obtained active carbons were determined. The ability of carbonaceous adsorbents for detoxification of soil against pesticides, purification of surface waters and for removal of organic pollutants from wastewaters has been evaluated. The obtained results reveal the effectiveness of their use in a number of environmental technologies.
\end{abstract}

Keywords: active carbon, vegetal raw byproducts, structural parameters, soil detoxification, water purification.

\section{Introduction} as a whole.

Progressive environmental pollution has made ecological safety an important component of the national security

Today, virtually the entire planet and especially the areas where people live are subject to serious environmental threats. The main ones are: radioactive contamination of territories, pollution of soil by acid rain, with chemicals and pesticides, oil spills on land and sea and the destruction of the atmosphere. Pollution of the biosphere dramatically reduces the quality of life and according to World Health Organization (2002), the factors affecting human health depend on: diet and lifestyle - $51 \%$, the environment - 39\%, medicine - $10 \%$.

In view of the above, the special attention should be paid to the environmental safety of the agrarian sector, providing the population with food, as farmland soils on the planet account for only $6 \%$ of the total land area, and the number of inhabitants at the end of the XXI century is expected to be 10 billions.

The problems of global environmental pollution were raised earlier by the Russian scientist Professor of MChTI "D. Mendeleev", N.V. Keltsev who offered the main way to solve the situation. He wrote: "At the moment when the question of life and death addresses not only the army, but all mankind, concerned by catastrophic pollution of the biosphere, it is time once again to turn for help to adsorption - one of the most effective methods of protecting the environment from pollution".

Due to their physico-chemical properties, carbonaceous adsorbents (activated carbons) are unique and ideal sorption materials, which allow solving a wide range of issues of chemical and biological safety, environmental and infrastructure issues [1].

Activated carbons (AC) - are highly porous materials obtained in the form of grains or powder of various carbon-based materials having high internal surface (up to $2500 \mathrm{~m}^{2} / \mathrm{g}$ ) and high absorbency towards impurities in the treated media (air, gas, water and other liquids, soil).

Among a wide variety of raw materials for the production of active carbon, in recent years the various vegetal wastes are of particular interest, as a constantly renewable source of raw materials.

In this research the technologies for active carbons production from major tonnage plant wastes: straw, nut shells and fruit stones, sawdust and products of hydrolysis of corn stalks and sunflower husk have been developed. Our research showed the effectiveness of their use in a number of environmental technologies.

\section{Experimental}

Activated carbons obtained from straw. In order to obtain active carbons from straw, the wheat straw, oat straw and rapeseed straw have been chosen as raw material. The technique was as follows. The straw was milled, loaded into a steel retort, which was capped and placed in the electric furnace, feeding nitrogen into the vessel to create an inert atmosphere. The retort was heated at a rate of temperature rise $1-20^{\circ} \mathrm{C} / \mathrm{min}$ to $450-500^{\circ} \mathrm{C}$ and maintained at the final carbonization temperature for 30-60 min. After completing the process of carbonization the retort was switched to the mode of steam activation at $850-870{ }^{\circ} \mathrm{C}$. 
Testing of active carbons from straw. The effectiveness of active carbons for the detoxification of soil from residues of applied herbicide has been evaluated [2]. The experiments were conducted in the laboratory of artificial climate (LAC) of the State Research Institute of Phytopathology RAAS (Golitsino, Moscow region). In order to sowing sunflower test culture, the pots with a capacity of $600 \mathrm{~g}$ of soil were used. The samples of soil were contaminated with the Singer herbicide in a dose corresponding to $5 \mathrm{~g} / \mathrm{ha}$. The tested active carbons were injected in a dose of $100 \mathrm{~kg}$ per 1 ha. After 30 days the average weight of the test plant was evaluated.

Activated carbons obtained from fruit stones. Active carbons from peach and apricot stones were obtained by steam activation method [1], which are proposed for respiratory protection filters.

Activated carbons obtained from sawdust. Activated carbons of brand "Carboline" with a high surface area of $2500 \mathrm{~m}^{2} / \mathrm{g}$, iodine adsorption capacity of 200-300\% and methylene blue absorption capacity of $600 \mathrm{mg} / \mathrm{g}$ have been obtained from sawdust or lignin by chemical activation method developed in the Northern Arctic Federal University (Arhangelsk).

Testing of active carbon "Carboline". Active carbon "Carboline" in its powder form is an indispensable adsorbent in the treatment of drinking water and waste waters. Laboratory tests were carried out in the laboratory of water purification at the Research Institute "Vodgeo" (Moscow).

Activated carbons obtained from hydrolysis products of corn cobs and sunflower husks. Preparation of activated carbon FAS was as follows: the mixture of furfural with sulfuric acid and active organic additives was performed in a mixer. Its volume was adjusted so that the residence time of the mixture therein didn't exceed the time of its gelation. The partially tarred composition flew by its gravity to a distributor and from its nozzles into a hot oil layer where it fragmented into droplets of the desired diameter depending on the viscosity. Final tarring and thermo set of the product in the reactor occurred in 15-18 seconds. The product separated by centrifugation from the oil, in the form of spherical grains of 2-3 mm, were sent to heat treatment and activation in a rotating electric furnace at a temperature of $850-870{ }^{\circ} \mathrm{C}$.

Standard test methods, including evaluation of ash content [3], bulk density [4], strength to abrasion [2,5], adsorption capacity for iodine and methylene blue (MB) $[2,5,6]$ have been used to characterize obtained activated carbon samples. Total pore volume $\left(\mathrm{V}_{\Sigma}\right)$ was determined by adsorption of water [7].

Sorption volume $\left(\mathrm{W}_{\mathrm{S}}\right)$, micropore $\left(\mathrm{V}_{\mathrm{mi}}\right)$ and mesopore volumes $\left(\mathrm{V}_{\text {meso }}\right)$ have been determined from nitrogen sorption isotherm by using the ASAP 2020 device (Micromeritics, USA) [2,8].

\section{Results and discussion}

Activated carbons obtained from straw (activated carbons of brand RAU)

Straw consumption by Russian economy significantly decreased. However, grain production gradually increases, and therefore increases the production of straw (in our country 80-100 million tons of straw accumulate each year only from grains and cereal crops). There is necessary for a rational solution to problems of post-harvest processing of soil and plant waste disposal, as currently they are simply burned or plowed into the ground.

Some physico-chemical characteristics of straw active carbons are presented in the Table 1. All obtained activated carbons are characterized by the development of the total pore volume $\left(\mathrm{V}_{\Sigma}\right)$, and a substantial expansion of the volume of sorption space $\left(\mathrm{W}_{\mathrm{s}}\right)$, wherein the actual volume of micropores $\left(\mathrm{V}_{\mathrm{mi}}\right)$ sized $0.8 \mathrm{~nm}$ is up to $0.16-0.20 \mathrm{~cm}^{3} / \mathrm{g}$, providing good indexes of the adsorption capacity for iodine and methylene blue (MB).

Table 1

Characteristics of activated carbons obtained from straw.

\begin{tabular}{lccccccc}
\hline Raw material & Bulk density, & $\mathrm{A}$ Ash, & \multicolumn{3}{c}{ Pore volume, $\mathrm{cm}^{3 / \mathrm{g}}$} & \multicolumn{3}{c}{ Adsorption capacity } \\
\cline { 5 - 8 } & $\mathrm{g} / \mathrm{dm}^{3}$ & $\mathrm{wt} \%$ & $\mathrm{~V}_{\Sigma}$ & $\mathrm{W}_{\mathrm{s}}$ & $\mathrm{V}_{\mathrm{mi}}$ & Iodine, \% & $\mathrm{MB}, \mathrm{mg} / \mathrm{g}$ \\
\hline Wheat straw & 66.5 & 12.2 & 3.61 & 0.73 & 0.20 & 64 & 52 \\
Oat straw & 72.5 & 28.2 & 3.97 & 0.44 & 0.16 & 50 & 44 \\
Canola straw & 135 & 16.5 & 4.17 & 0.48 & 0.16 & 39 & 87 \\
\hline
\end{tabular}

The results of testing experiments of active carbons for detoxification of soils are shown in Table 2. Obtained results show that the growth inhibition (in comparison with blank control) in the case of the application of active carbons from wheat and oat straw, on soils contaminated by herbicides (using Singer as an example), represent only 4.9\%, while in the case of the world- recognized active carbon Grosafe for soil destination, it reaches $12.2 \%$. These results suggest that the effectiveness of active carbons obtained from straw is about 2.5 times higher than of the active carbon Grosafe used for soils detoxification. 
Effect of activated carbons on the phytotoxicity of methsulfuron - methyl (Singer, SP) on the example of sunflower plants (September, 2013).

\begin{tabular}{lcc}
\hline Experiment & Average mass, $\mathrm{g}$ & \% to control \\
\hline Singer, SP & 1.1 & 73.2 \\
Singer, SP + AC from oat straw & 3.9 & 4.9 \\
Singer, SP + AC from wheat straw & 3.9 & 4.9 \\
Singer, SP + AC from canola straw & 3.2 & 21.9 \\
Singer, SP + AC Grosafe & 3.6 & 12.2 \\
Control (no herbicides) & 4.1 & - \\
\hline
\end{tabular}

Activated carbons obtained from nutshells and fruit stones (activated carbons of brand MeKS)

It is known that the best active carbons from nutshells are ones derived from coconut shells. Because this kind of vegetal raw material is missing in Europe, we chose the same type of compacted plant material: stones of peach and apricot - and we obtained active carbon prototypes by steam activation. The physico-chemical and adsorption properties of obtained active carbons from fruit stones in comparison with activated carbons from coconut shells of brand GCN830 (Norit, The Netherlands) are presented in Table 3.

Table 3

Characteristics of activated carbons obtained from coconut shells and fruit stones.

\begin{tabular}{|c|c|c|c|c|c|c|c|}
\hline \multirow[t]{2}{*}{ Raw material } & \multirow{2}{*}{$\begin{array}{l}\text { Bulk density, } \\
\mathrm{g} / \mathrm{dm}^{3}\end{array}$} & \multirow{2}{*}{$\begin{array}{l}\text { Strength to } \\
\text { abrasion, \% }\end{array}$} & \multirow{2}{*}{$\begin{array}{l}\text { Ash, } \\
\text { wt } \%\end{array}$} & \multicolumn{2}{|c|}{ Pore volume, $\mathrm{cm}^{3} / \mathrm{g}$} & \multicolumn{2}{|c|}{ Adsorption capacity } \\
\hline & & & & $\mathrm{V}_{\Sigma}$ & $\mathrm{V}_{\mathrm{mi}}$ & Iodine, $\%$ & $\mathrm{MB}, \mathrm{mg} / \mathrm{g}$ \\
\hline Apricot & 395 & 94.0 & 4.6 & 0.89 & 0.52 & 111 & 290 \\
\hline Peach & 394 & 93.6 & 2.4 & 0.90 & 0.50 & 110 & 295 \\
\hline Coconut & 410 & 90.3 & 2.7 & 0.85 & 0.57 & 110 & 270 \\
\hline
\end{tabular}

As shown in Table 3, activated carbons from fruit stones (within the measurement error - 10\%) are on the same level with the activated carbons from coconut shells. This gives us the opportunity to create on their basis individual and collective respiratory protection of filter type, since it is known that the best gas masks are created using activated carbons obtained from coconut shells.

\section{Activated carbons obtained from sawdust (activated carbons of brand "Carboline")}

The total volume of wood waste in Russia is around 150 million $\mathrm{m}^{3} /$ year, the proportion of sawdust and lignin being not less than 50 million $\mathrm{m}^{3} /$ year. The characteristics of the obtained activated carbons (by chemical method of activation) in comparison with industrial analogues are presented in Table 4. As follows from the obtained data, the value of the main quality indicators of "Carboline" is much higher than that for the traditionally used in Russia active carbons OU-A, UAF, in fact by 2-3 times.

Active carbon "Carboline" in its powder form is an indispensable adsorbent in the treatment of drinking water and sewage from organic pollutants. Test results of active carbon "Carboline" for compliance with active carbons used for purification of drinking water are presented in Table 5.

Table 4

Characteristics of activated carbon samples prepared by chemical activation.

\begin{tabular}{lcccc}
\hline \multicolumn{1}{c}{ Characteristics } & "Carboline" & OU-A & UAF & $\begin{array}{c}\text { World level } \\
\text { PHOM200 (UK) }\end{array}$ \\
\hline 1. Raw material & Sawdust & Birch Coal & Black coal & Coconut shell \\
2. Adsorption capacity for iodine, $\%$ & 235 & 70 & 70 & 103 \\
3. Adsorption capacity for $\mathrm{MB}, \mathrm{mg} / \mathrm{g}$ & 604 & 225 & 190 & 246 \\
4. Ash content, $\%$ & 2.3 & 10.0 & 11.5 & 2.6 \\
5. Content of compounds of $\mathrm{Fe}^{3+}, \%$ & 0.09 & 0.2 & - & 0.04 \\
6. Water content, $\%$ & 0.3 & 10.0 & 5.0 & 5.6 \\
7. Bulk density, g/dm & 212 & - & - & 320 \\
8. Fineness (sieve residue $0.1 \mathrm{~mm}), \%$ & 18 & 5 & 5 & 1 \\
9. pH & 3 & $4-6$ & $8-9$ & $9-11$ \\
\hline
\end{tabular}

*Activated carbon obtained according to GOST 4453-74;

${ }^{* *}$ Activated carbon obtained according to TS 2162-010-22931414-01. 
Results of testing “Carboline” activated carbons for compliance with requirements towards active carbons used for purification of drinking water.

\begin{tabular}{llcc}
\hline No. & Characteristics & Required & Result \\
\hline 1 & Adsorption capacity for iodine, $\mathrm{mg} / \mathrm{g}$, not less & 880.0 & 1266.0 \\
2 & Adsorption capacity for MB, $\mathrm{mg} / \mathrm{g}$, not less & 220.0 & 386.0 \\
3 & Water content, wt $\%$, not more & 10.0 & 3.9 \\
4 & Ash content, wt $\%$, not more & 10.0 & 2.35 \\
5 & Water-soluble ash, wt $\%$, not more & 2.0 & 0.5 \\
\hline
\end{tabular}

Given that currently the use of powder forms of activated carbons is increasing on water channels in Russia and the rest of the world, the powdered coal "Carboline" with such high adsorption performance has great application prospects.

Activated carbons obtained from hydrolysis products of corn cobs and sunflower husks (activated carbons of brand FAS)

One of the most promising synthetic materials is furfural - product of primary processing of pentosanecontaining plant material, primarily corn cobs and sunflower husks. Due to the availability of raw materials and the high reactivity of furfural, it is one of the most popular products on the world market for the production of a variety of monomeric and polymeric materials. Its presence in the Russian Federation, which has considerable and reproducible reserves of vegetal raw materials for large-scale production of furfural, proves the possibility of using it to develop an industrial technology for producing carbon adsorbents characterized by significantly improved mechanical and adsorptive properties in comparison with well-known brands of activated carbons.

The characteristics of activated carbons FAS of progressive activation are shown in Table 6, in comparison with two commercially available active carbons: (i) based on black coal - F- 400 (Calgon Carbon Corp., USA) and (ii) birch wood BAU-A (JSC “Sorbent”, Russian Federation).

\section{Comparative characteristics of the spherical carbonaceous adsorbent FAS with domestic and imported AC.}

\begin{tabular}{|c|c|c|c|c|c|c|c|c|}
\hline \multirow{3}{*}{ Sample } & \multirow{3}{*}{$\begin{array}{l}\text { Bulk density, } \\
\qquad \mathrm{g} / \mathrm{dm}^{3}\end{array}$} & \multirow{3}{*}{$\begin{array}{l}\text { Strength to } \\
\text { abrasion, } \%\end{array}$} & \multirow{3}{*}{$\begin{array}{l}\text { Ash, } \\
\mathrm{wt}^{2} \%\end{array}$} & \multicolumn{5}{|c|}{ Pore volume } \\
\hline & & & & \multirow{2}{*}{$\begin{array}{c}\mathrm{V}_{\Sigma} \\
\mathrm{cm}^{3} / \mathrm{g}\end{array}$} & \multicolumn{2}{|c|}{$\mathrm{V}_{\mathrm{mi}}$} & \multicolumn{2}{|c|}{$\mathrm{V}_{\text {meso }}$} \\
\hline & & & & & $\mathrm{cm}^{3} / \mathrm{g}$ & $\mathrm{cm}^{3} / \mathrm{cm}^{3}$ & $\mathrm{~cm}^{3} / \mathrm{g}$ & $\mathrm{cm}^{3} / \mathrm{cm}^{3}$ \\
\hline FAS & 509 & 99.7 & 0.03 & 0.92 & 0.45 & 0.23 & 0.47 & 0.24 \\
\hline FAS & 436 & 98.8 & 0.05 & 1.09 & 0.56 & 0.24 & 0.53 & 0.23 \\
\hline FAS & 345 & 98.0 & 0.08 & 1.50 & 0.80 & 0.28 & 0.70 & 0.24 \\
\hline BAU-A & 240 & 37.0 & 6.0 & 1.60 & 0.23 & 0.07 & 0.09 & 0.02 \\
\hline F-400 & 420 & 82.0 & 7.0 & 0.80 & 0.32 & 0.13 & 0.12 & 0.05 \\
\hline
\end{tabular}

Outstanding strength and adsorption characteristics of FAS, especially micropore volume per unit volume $\left(\mathrm{cm}^{3} / \mathrm{cm}^{3}\right)$ which are 2-3 times higher than of industrial active carbons, together with almost zero ash content, opens tremendous opportunities for solving problems of protection from atmospheric emissions, hydrosphere, lithosphere and the man himself as the main object of biosphere.

\section{Conclusions}

The performed research on the preparation and usage of activated carbons obtained from renewable raw materials reveals the ability of carbonaceous adsorbents for detoxification of soil against pesticides, purification of surface waters and for removal of organic pollutants from wastewaters.

\section{References}

1. Mukhin, V.M.; Klushin V.N. Production and use of carbonaceous adsorbents. Moscow: PHTU D.I. Mendeleev, 2012, 305 p. (in Russian).

2. Mukhin, V.M.; Tarasov A.V.; Klushin V.N. Active carbons of Russian Federation. Moscow: Metallurgy, 2000, 352 p. (in Russian).

3. GOST 12596-67 Method for determination of the ash content (in Russian).

4. GOST 16190-70 Method of bulk density determination (in Russian).

5. GOST 4453-74 Wood powder active carbon. Technical specifications (in Russian).

6. GOST 6217-74 Adsorption capacity towards iodine (in Russian).

7. GOST 17219-71 Method for determination of the total pore volume towards water (in Russian).

8. MI 6-16-2795-84 Determination of the effective volume micropore of activated carbons (in Russian). 